\title{
Why do most patients with atrial fibrillation referred for other cardiac surgery not receive concomitant ablation? A plea for a more aggressive surgical approach
}

\author{
Ralph J. Damiano, Jr, MD
}

See related article on pages 3027-33.

This is another in a series of important contributions from Dr Ad and his group examining the efficacy of the Cox-Maze procedure in different patient populations. ${ }^{1}$ There has been a popular prejudice among surgeons that performing a Cox-Maze I procedure in high-risk patients adds to morbidity and mortality without real benefit. This belief can be traced back to the historical results with the original cut-and-sew Cox-Maze III procedure. There is no doubt that this was a complex, difficult operation that required a long period of crossclamping, and few surgeons considered adding this operation when performing other concomitant cardiac procedures. In 2003, Prasad and colleagues $^{2}$ reported the results from St Louis with the Cox-Maze III procedure. The average crossclamp time was 90 minutes for a lone Maze III procedure, with the majority of these patients undergoing operation by the originator of this operation, Dr James Cox. In the hands of less expert surgeons, this procedure often required even more time. The mortality rate was $2 \%$ with a major complication rate of $12 \%$. With the introduction of the ablation-assisted Maze IV procedure in 2004, there has been a dramatic decrease in both the difficulty of the operation and the time required to complete the full lesion set. $^{3}$ In comparing our experience with the stand-alone Cox-Maze IV with the Cox-Maze III procedure, we found that the crossclamp time was nearly cut in half, with a significant decrease in the major complication rate from $10 \%$ to $1 \%$. ${ }^{4}$ By using ablation devices to simplify the procedure, this operation can now be widely applied to a broader spectrum of patients with excellent results. However, few reports have looked at the safety and efficacy of the Cox-Maze procedure in high-risk patients. In this

From the Division of Cardiothoracic Surgery, Washington University School of Medicine, Barnes Jewish Hospital, Barnes Jewish Hospital, St Louis, Mo.

Disclosures: Ralph J. Damiano, Jr, is a consultant for Atricure.

Received for publication Oct 20, 2014; accepted for publication Oct 21, 2014

Address for reprints: Ralph J. Damiano, Jr, MD, Division of Cardiothoracic Surgery, Washington University School of Medicine, Suite 3108, Queeny Tower,

Barnes-Jewish Hospital Plaza, St Louis, MO 63110 (E-mail: daminor@wustl.edu). J Thorac Cardiovasc Surg 2014;148:3034-5

0022-5223/\$36.00

Copyright (c) 2014 by The American Association for Thoracic Surgery

http://dx.doi.org/10.1016/j.jtcvs.2014.10.092 excellent report examining their single-center results in 370 patients, Dr Ad and colleagues found no significant differences in morbidity or mortality among the low-risk, intermediate-risk, and high-risk patients. ${ }^{1}$ Moreover, the procedure had similar efficacy in terms of restoration of sinus rhythm in all of the groups.

These important data hopefully will lead to surgeons having a more aggressive attitude to performing Maze procedures in patients referred for other cardiac surgery. There is overwhelming evidence that surgeons are still reluctant to perform concomitant surgical ablation. In studies examining the Society of Thoracic Surgeons database, only approximately $20 \%$ to $39 \%$ of patients with atrial fibrillation have surgical ablation at the time of surgery. ${ }^{5}$ Although this may have been appropriate with the historical Cox-Maze III procedure, it ignores the advances that have occurred with the introduction of both ablation devices and less-invasive approaches. It is time for surgeons to reassess their preconceptions and be more open to performing ablation for atrial fibrillation at the time of concomitant cardiac surgery. As surgeons, we have the unique opportunity to restore sinus rhythm and improve the quality of life in these patients. The Cox-Maze procedure remains the single most efficacious intervention for atrial fibrillation. This report and others have provided evidence that both low-risk and high-risk patients benefit in a similar fashion. ${ }^{1}$ Hopefully, surgical practice will begin to reflect these advances, and more patients will be thought to be candidates for this important therapeutic intervention.

There are 2 caveats that need to be emphasized regarding this recommendation. First, these results are from a single center, in which a very experienced surgeon performed the majority of the procedures. Whether similar results can be obtained at less-experienced centers remains to be established. The superb outcomes in this report emphasize the importance of both surgeon experience and defining late outcomes. ${ }^{1}$ This is an operation in which success or failure is defined as freedom from atrial fibrillation at 12 months. To obtain this information, a center needs to make a significant investment and commitment to obtain adequate follow-up. This requires a longitudinal database and a dedicated team.

The second point of emphasis is that these results were obtained with a full Cox-Maze lesion set. Unfortunately, the majority of patients receiving surgical ablation for atrial 
fibrillation receive a more limited ablation, either a left atrial lesion set alone or a pulmonary vein isolation. In concomitant patients, these procedures have been significantly less efficacious in our experience. ${ }^{6}$ Surgeons should be careful in extrapolating these excellent results to patients who do not receive a full Cox-Maze lesion pattern.

This excellent case series adds further information supporting the safety and efficacy of the Cox-Maze procedure in both low- and high-risk patients who are referred for concomitant surgery. ${ }^{1}$ It is time for the surgical community to translate these results into their clinical practice and offer the Cox-Maze procedure to most patients with atrial fibrillation who are referred for concomitant cardiac surgery.

\section{References}

1. Ad N, Holmes SD, Pritchard G, Shuman DJ. Association of operative risk with the outcome of concomitant Cox Maze procedure: A comparison of results across risk groups. J Thorac Cardiovasc Surg. 2014;148:3027-33.

2. Prasad SM, Maniar HS, Camillo CJ, Schuessler RB, Boineau JR, Sundt TM III et al. The Cox-Maze III procedure for atrial fibrillation: long-term efficacy in patients undergoing lone versus concomitant procedure. J Thorac Cardiovasc Surg. 2003;126:1822-8

3. Gaynor SL, Diodato MD, Prasad SM, Ishii Y, Schuessler RB, Bailey MS, et al. A prospective, single center clinical trial of a modified Cox-Maze procedure using bipolar radiofrequency ablation. J Thorac Cardiovasc Surg. 2004;128:535-42.

4. Weimar T, Schena S, Bailey MS, Maniar HS, Schuessler RB, Cox JL, et al. The Cox-Maze procedure for lone atrial fibrillation: a single center experience over 2 decades. Circ Arrhythm Electrophysiol. 2012;5:8-14.

5. Ad N, Suri RM, Gammie JS, Sheng S, O'Brien SM, Henry L. Surgical ablation of atrial fibrillation trends and outcomes in North America. J Thorac Cardiovasc Surg. 2012;144:1051-60

6. Melby SJ, Zierer A, Bailey MS, Cox JL, Lawton JS, Munfakh N, et al. A new era in the surgical treatment of atrial fibrillation: the impact of ablation technology and lesion set on procedural efficacy. Ann Surg. 2006;244:583-92. 